\title{
Quantifying Embodied Technological Change ${ }^{1}$
}

\author{
Plutarchos Sakellaris \\ University of Maryland and University of Ioannina \\ and \\ Daniel J. Wilson
}

Federal Reserve Bank of San Francisco

\begin{abstract}
:
We estimate the rate of embodied technological change directly from plant-level manufacturing data on current output and input choices along with histories on their vintages of equipment investment. Our estimates range between 8 and 17 percent for the typical U.S. manufacturing plant during the years 1972-1996. Any number in this range is substantially larger than is conventionally accepted with some important implications. First, the role of investmentspecific technological change as an engine of growth is even larger than previously estimated. Second, existing producer durable price indices do not adequately account for quality change. As a result, measured capital stock growth is biased. Third, if accurate, the Hulten and Wykoff (1981) economic depreciation rates may primarily reflect obsolescence.
\end{abstract}

Keywords: productivity growth, embodied technological change, equipment investment, plant, producer durable price index.

JEL: O3, D24, L60

${ }^{1}$ Correspondence: plutarch@electra.umd.edu. This is a revised version of a paper previously circulated as "The Production-Side Approach to Estimating Embodied Technological Change." We would like to thank Carol Corrado, Boyan Jovanovic, and seminar participants at Athens University of Economics and Business, University of Ioannina, Koc University, University of Maryland, New York University, European Central Bank, Federal Reserve Banks of Boston and San Francisco, Federal Reserve Board, Center for Economic Studies (CES), U.S. Census Bureau for very useful comments. Plutarchos Sakellaris would like to thank the staff of the Industrial Output Section of the Federal Reserve Board for their hospitality while he was working on this paper. Daniel Wilson would like to thank Clopper Almon and the staff of Inforum for their generous support, financial and otherwise, of this research. The data used in this paper were collected under the provisions of Title 13 US Code and are only available at the CES. The research in this paper was conducted by the authors as Research Associates at the CES. The views expressed here do not represent those of the Federal Reserve System, its staff, or the U.S. Census Bureau. 


\section{Introduction}

Johansen (1959) and Solow (1960) argued that more recent vintages of capital may embody technological advances that make them "better", or equivalently "of higher quality", than older vintages. In that case, investment is essential in order to reap benefits from the part of technological progress that is embodied in capital. The distinction between embodied and disembodied technological change is important in analyzing many issues related to long-run standards of living and growth. ${ }^{2}$

Jovanovic and Rob (1999) show that distortions to investment incentives have a substantially larger effect when technological growth is embodied in equipment. In particular, the taxation of equipment plays a big role in explaining development gaps across countries. Eaton and Kortum (2001) attribute about 25 percent of cross-country productivity differences to variation in the relative price of equipment, about half of which they ascribe to barriers to trade in equipment that inhibit the diffusion of embodied technological change across borders.

The decomposition of technological change to embodied and disembodied may be important for understanding medium-run growth experience, as well. From 1995 to 1999 U.S. labor productivity and total factor productivity (TFP) grew at rates about double those of the preceding 20 years. This dramatic change has lead to some important questions. What are the reasons for this productivity surge? Is it going to be long lasting?

A possible explanation for this surge in productivity growth assigns a big role to equipment investment. The U.S. economy experienced an equipment investment boom in the middle and late 1990's. Investment in equipment and software averaged 9.6 percent of GDP

\footnotetext{
${ }^{2}$ Throughout this paper we will be using the terms embodied and investment-specific technological change interchangeably.
} 
between 1995 and 1999, 3.2 percentage points higher than the average from 1987-94. Much of this new equipment was for Information Technology but other types of equipment were also purchased en masse. If new equipment embodies technology that is more productive on the margin than that of older equipment and official price indices do not fully reflect such quality changes then an equipment investment boom should be accompanied by an increase in measured TFP growth. TFP will grow faster than average for as long as the rates of investment are heightened.

There is another possibility for sustainably high TFP growth rates within this framework. If the rate of growth of technology that is embodied in new vintages of investment has increased then at any rate of equipment investment measured TFP growth will be higher. ${ }^{3}$ Some have argued that the advent of Information Technology (the computer revolution) and its incorporation into production has slowly pushed the average rate of embodied technological change higher (see Greenwood and Yorukoglu, 1997, among others).

A serious shortcoming in the above discussion has been the lack of reliable estimates of the rate of technological change that is embodied in equipment capital. Most of the literature on embodiment, including the papers of Hulten (1992) and Greenwood, Hercowitz, and Krusell (1997), has relied on an estimate of about 3 percent for the years 1954 to 1990. This estimate was derived by comparing the rates of growth of either a consumption deflator or the official price index for equipment investment (which turn out to be quite similar) with another one constructed by Gordon (1990), which is intended, inter alia, to capture change in the quality of new vintages of equipment. However, as Gordon (1996) points out, the difference in the growth

\footnotetext{
${ }^{3}$ Again it is important for this argument to go through that official price indices due not incorporate quality growth adequately.
} 
rates of his index and either of the other two is not due to quality change alone. Furthermore, not all kinds of quality change are captured by the Gordon (1990) index. ${ }^{4}$

In this paper, we propose an estimation framework that arrives at estimates of the rate of growth of embodied technological change directly from observed production, input, and investment decisions at the plant level. If there are vintage effects (embodiment) then plants with relatively newer equipment should be more productive, after controlling for materials, labor input and utilization of capital and labor. These effects may be estimated in a production function framework where the capital stock of equipment is not constructed using the perpetual inventory method. Instead, we include in the estimating equation the complete history of investment in equipment by vintage, deflated by a deflator that does not correct for any quality change.

The result that we obtain is that each vintage is about 12 percent more productive than the previous year's vintage (in the preferred specification). This number is astounding compared to the commonly accepted 3 percent based on Gordon's (1990) series. ${ }^{5}$ We evaluate the impact of embodied technological change on US manufacturing productivity growth between 1972 and 1996. We estimate that the effective capital stock of equipment grew about three times faster than commonly estimated and that the contribution of embodied technological change to total technological change was about two thirds. These findings have several important implications. First, the role of investment-specific technological change as an engine of growth is even larger

${ }^{4}$ See Section 3 for further discussion on the use of Gordon's index to capture embodied technological change.

${ }^{5}$ A notable exception is Bahk and Gort (1993) who also estimate a high rate of embodied technological growth. 
than previously estimated. Second, existing producer durable price indices substantially

mismeasure quality change, yielding downward biased measures of capital stock growth. Lastly, assuming Hulten and Wykoff's (1981) estimates of economic depreciation, which have since been adopted by the U.S. Bureau of Economic Analysis (BEA), are correct, our estimates suggest that obsolescence is the most important factor in the decline of the average capital asset's value over time.

\section{A two-sector model of investment-specific technological change ${ }^{6}$}

In order to formalize the concept of capital-embodied technological change we consider a two-sector model where one sector produces investment goods $(\widetilde{i})$ and the other produces consumption goods (c). Each good is produced using capital (k) and labor (l) as inputs according to the following production functions:

$$
\begin{gathered}
\tilde{\mathrm{i}}_{\mathrm{t}}=\mathrm{z}_{\mathrm{t}} \mathrm{q}_{\mathrm{t}} \tilde{\mathrm{k}}_{\tilde{\mathrm{i}}, \mathrm{t}}^{\alpha} 1_{\tilde{\mathrm{i}}, \mathrm{t}}^{1-\alpha} \\
\mathrm{c}_{\mathrm{t}}=\mathrm{z}_{\mathrm{t}} \tilde{\mathrm{k}}_{\mathrm{c}, \mathrm{t}}^{\alpha} 1_{\mathrm{c}, \mathrm{t}}^{1-\alpha}
\end{gathered}
$$

where $\mathrm{z}$ is the level of technology common to both sectors whereas $\mathrm{q}$ is technological level specific to the investment sector? A " " denotes that the variable is defined in terms of

${ }^{6}$ The exposition in this section follows Hornstein and Krusell (1996), Greenwood et al. (1997), and Hercowitz (1998). For clarity, we do not make a distinction here between structures and equipment investment, though in the empirical work this distinction will be crucial.

${ }^{7}$ Greenwood et al. (1997) discuss conditions under which the economy exhibits balanced growth with or without exogenous technological change. 
efficiency units. For simplicity, $\alpha$, the elasticity of output with respect to capital is assumed to be the same in both sectors. ${ }^{8}$ Assume that all factors of production are perfectly mobile across sectors and that perfect competition holds in all markets. Then, as a result of factor price equalization, the price of investment goods relative to consumption goods is: $\mathrm{P}_{\mathrm{t}}^{\tilde{\mathrm{i}}} / \mathrm{P}_{\mathrm{t}}^{\mathrm{c}}=1 / \mathrm{q}_{\mathrm{t}}$. Thus, one may compute the rate of growth of investment-specific (capital-embodied) technological change from the rate of decline in the relative price of investment goods.

Figure 1 graphs the Personal Consumption Expenditures (PCE) deflator from the National Income and Product Accounts (NIPA) and an average equipment-investment price index for manufacturing. The latter is an average, over our plant-level sample, of the 3-digit industry equipment-investment deflators constructed by the Federal Reserve Board (FRB) using industry investment-by-asset type data from the BEA and Producer Price Indexes (PPI) for asset types ${ }^{9}$. Oddly enough, these two indexes grow about the same rate between 1972 and $1996^{10}$.

${ }^{8}$ Hornstein and Krusell (1996) show the implications of allowing $\alpha$ to differ by sector.

${ }^{9}$ The FRB industry-level deflators are matched to the plant-year records in our sample according to the 3-digit industry to which a plant belonged in that year. For each year between 1972 and 1996 (the investment years covered by our sample), we take the within-year, crosssectional mean of the equipment-investment price deflators. Thus, for any particular year, this mean can be thought of as a weighted average of the FRB's 3-digit deflators where the weights are the fraction of our sample in each 3-digit industry. An unweighted average is nearly identical.

${ }^{10}$ The average growth rate of the PCE deflator is about $5.3 \%$ per year. The equipmentinvestment price index grows at about $5.1 \%$ per year and is very similar to the deflator for "Industrial Equipment" in NIPA, which grows at 5.5\% per year. It is interesting to note that the two price indices in Figure 1 display distinctly different behavior in two subperiods. Between 1972 and 1981 equipment-investment prices rose 2.25 percent per year compared to consumption goods whereas from 1982 to 1996 they fell 1.67 percent per year. 
Does this mean that there was no embodied technological change during this period? Several authors provided a negative answer arguing that the official price indexes for PDE grow too fast as a result of mismeasurement. These authors use, instead, equipment-investment price indexes constructed by Gordon (1990) to reflect quality change. The drop in the price of equipment (relative to the PCE deflator) suggested by Gordon's index implies a rate of embodied technological change of $3.2 \%$. However, the comparison of the above two price indexes is not the only way to ascertain the importance of embodiment. We provide below and in section (4) an alternative approach relying on data on produced output and utilized inputs .

Since the production function is homogeneous of degree one and the capital-labor ratio is equal across sectors one can write total output in terms of consumption goods as:

$$
\frac{\tilde{\mathrm{i}}_{\mathrm{t}}}{\mathrm{q}_{\mathrm{t}}}+\mathrm{c}_{\mathrm{t}}=\mathrm{y}_{\mathrm{t}}=\mathrm{z}_{\mathrm{t}} \tilde{\mathrm{k}}_{\mathrm{t}}^{\alpha} \mathrm{l}_{\mathrm{t}}^{1-\alpha}
$$

Note that capital input, $\mathrm{k}$, in the above expression is defined in efficiency units (i.e. in terms of investment goods):

$$
\tilde{\mathrm{k}}_{\mathrm{t}}=(1-\delta) \tilde{\mathrm{k}}_{\mathrm{t}-1}+\mathrm{i}_{\mathrm{t}} \mathrm{q}_{\mathrm{t}}
$$

where $\delta$ is the geometric rate of physical depreciation ${ }^{11}$. In order to construct the capital stock correctly one needs to adjust each vintage of investment for quality change that is due to

\footnotetext{
${ }^{11}$ This concept comes in many other names, for example, physical decay, or depreciation from use. It is not equivalent to economic depreciation, which includes the effect of obsolescence as well.
} 
investment-specific technological change. The above expression for total output demonstrates that this two-sector economy is equivalent to a one-sector economy where (disembodied) technological change is captured by $\mathrm{z}_{\mathrm{t}}$ and output saved as capital is enhanced (in terms of efficiency) by capital-embodied technological change, $\mathrm{q}_{\mathrm{t}}$. The society can only take advantage of this latter form of technological change by forgoing consumption and investing in capital.

\section{A new method to identify q:}

Equations (3) and (4) suggest an alternative way to estimating embodied technological change, $\mathrm{q}_{\mathrm{t}}$, without the use of a price index for equipment investment. One may estimate the $\mathrm{q}$ series econometrically with plant level data, say, on output and current and past investment measured in terms of consumption in addition to data on labor input. There are four important elements to this approach:

1) Deflate output and investment by a price index that does not adjust for quality change.

2) Apply depreciation adjustments to capital that capture physical deterioration but not obsolescence.

3) Allow the marginal productivity of each vintage to be freely estimated.

4) Use the estimated residual to identify disembodied technological change.

\section{Related Literature}

One could classify the set of related papers into two camps. Most of the recent contributions use Gordon's (1990) quality-adjusted price indices for PDE in order to identify embodied technological change and then answer important questions related to economic growth or fluctuations in the U.S. The second camp contains older contributions that estimated 
embodied technological change using data on production and capital stock age using an approach due to Nelson (1964). We review these two camps briefly here and point out the main differences of our approach.

\section{Price-Based Estimates of Embodied Technological Change}

Gordon (1990) is a major study aimed at correcting mismeasurement in equipment price indices due to quality change. He provides quality-adjusted price indices for 22 types of equipment and their components. Hulten (1992) was the first to use these series in order to identify embodied technological change. He constructed a single aggregate index from Gordon's indices as well as one for the corresponding price indices published by BLS. Taking the ratio of the two, he calculated the average annual growth rate of embodied technological change to be 3.44 percent for U.S. manufacturing during 1949-1983. As a result, he attributed about 20 percent of the residual growth of quality-adjusted manufacturing gross output to embodied technological change.

Various papers followed Hulten (1992) in using Gordon's data but differed in the methodology employed. Greenwood et al. (1997) argued that the baseline index for comparison should be the implicit price deflator for non-durable consumption goods. This had very little effect on their estimate of embodied technological change. Three other differences in methodology, however, were important. Greenwood et al. (1997) advocated that output not be adjusted for quality change, that value added data be used in place of gross output and that a general equilibrium approach be used that accounts for input growth due to embodied technological change. They found that embodied technological change contributed about 58 
percent of all output growth in the U.S. between 1954 and $1990^{12}$.

Hornstein and Krusell (1996) and Greenwood and Yorukoglu (1997), among others, note that the Gordon index points to a large increase in the rate of embodied technological change after $1973^{13}$. They argue that increased technological change and the adjustment processes necessitated by it are largely responsible for the post-1973 measured slowdown in productivity growth. Greenwood et al. (2000) use Gordon's data to investigate the importance of embodied technological change for postwar U.S. aggregate fluctuations. They document a negative comovement between the relative price of equipment and equipment investment. Their analysis suggests that about 30 percent of output fluctuations are due to shocks in this relative price. ${ }^{14}$

The practice of using Gordon's (1990) quality-adjusted price indices for PDE in order to identify embodied technological change is not uncontroversial. Gordon (1996) takes issue with it. He claims that differences between his indices and the official ones are not entirely due to quality change. He offers as an example the traditional substitution bias introduced by a change in the relative prices of goods. Furthermore, he continues, quality adjustment may arise for reasons unrelated to embodied technological change. For example, an energy price increase may lead consumers to shift from inexpensive and energy-inefficient air conditioners to expensive and energy-efficient ones. The latter are also more costly to produce at any given level of technology in the equipment-producing sector (denoted $\mathrm{q}_{\mathrm{z}_{\mathrm{t}}}$ in our two-sector model) and do not

\footnotetext{
${ }^{12}$ Disembodied change provided the rest. The authors actually use the terminology investment-specific versus neutral technological change.

${ }^{13}$ This increase is about 25 percent. See, e.g., Hornstein and Krusell (1996) p. 231.

${ }^{14}$ There are several related papers. See Greenwood et al. (2000) pp. 110-2 for a partial review.
} 
necessarily represent an increase in technology.

Finally not all kinds of quality change are captured by the Gordon index. Gordon was only able to create new price indices for durable goods for which sufficient data on model characteristics and prices existed. The Sears catalog was the primary source of this data. For a large number of goods there simply was no data. ${ }^{15}$ Given these problems, it seems fruitful to examine alternative methods of estimating embodied technological change.

\section{Production-Based Estimates of Embodied Technological Change}

Nelson (1964) developed a variant of Solow's (1960) embodiment model that illustrated the relationship between the rate of embodied technological change and the average age of capital. He showed that, to an approximation, the log of efficiency-adjusted capital ( $\mathfrak{k})$ is proportional to a time trend plus the difference of $\gamma \mathrm{a}_{\mathrm{t}}$ and the $\log$ of unadjusted capital $(\mathrm{k})$, where $\mathrm{a}_{\mathrm{t}}$ is the average age of the unadjusted capital stock. Thus, a standard production function estimation (in logs) provides an estimate of embodied technological change by dividing the coefficient on average age by the coefficient on capital stock. Bahk and Gort (1993) study a sample of young manufacturing plants and find that a 1-year drop in average age is associated with between a 2.5 and a 3.5 percent rise in the plant's gross output (See their Table 1 and p. 571). Assuming a one-sixth share weight for capital in the production function of gross output, these results correspond to a 15-21 percent annual rate of growth of embodied technological

\footnotetext{
${ }^{15}$ Gort and Wall (1998) argue that estimates of embodied technological change based on Gordon (1990) may be biased substantially towards zero (pp. 1658-9). They also point out another problem with the group of studies applying this methodology. While they adjust investment flows for quality change, they implicitly assume that economic depreciation rates, derived from Hulten and Wykoff (1981) and incorporated in the NIPA, measure only physical decay. This is unlikely to be true as these measures also incorporate obsolescence, in principle.
} 
change. This is five to seven times higher than the price-based estimates discussed above.

However, Bahk and Gort (1993) make the dubious assumption that maintenance outlays offset the effect of physical decay on the capital stock. Their capital stock construct is the sum of gross investments of all vintages without any adjustment for physical depreciation ${ }^{16}$. Their estimates are best regarded as describing the joint impact of physical depreciation and embodiment. Our view is that physical decay occurs at a rate higher than zero.

A recent paper by Hobijn (2001) is an interesting addition in this strand of the literature. Using data for 4-digit US manufacturing he estimates the rate of embodied technological change from an equation derived from the investment Euler equation. He finds estimates that average about 12 percent. As we will see in Section 6, this is remarkably close to our preferred estimate for US manufacturing.

\section{Our Methodology}

The elusive holy grail of the embodiment literature has been independent estimates of embodied technological change. Our approach is to estimate that from production data. It involves exploiting the cross-sectional and time-series variation in plant-level historical investment distributions in order to estimate the relative levels of technology embodied in particular vintages of investment.

A simple example will help illustrate the basic concept. Consider two plants, A and B, both born in 1980 and observed continuously until 1989 (inclusive). Plant A expended 55\% of

${ }^{16}$ While they admit that "this assumption is only at best an approximation of reality" (p.566) they do not provide concrete supporting evidence for it. 
its lifetime (up to 1989) investment in 1980 and 5\% in each year thereafter. In contrast, plant B invested 55\% in 1989 and 5\% in each prior year. The plants are otherwise identical. One can exploit the variation in these two plants' vintage distributions in investment (net of physical decay) to estimate embodied technological change by comparing their output in 1989 . Doms \& Dunne (1998) provide empirical evidence of this kind of variation in investment. They find that over a 17-year period, $50 \%$ of the average plant's investment is concentrated in 3 years (not necessarily consecutive). Furthermore, lumpy investment activity is not synchronized across plants.

We now formalize the production approach. Consider a Cobb-Douglas function for the production of plant output:

$$
\mathrm{y}_{\mathrm{it}}=\beta \cdot 1_{\mathrm{it}}+\theta \cdot \mathrm{m}_{\mathrm{it}}+\alpha \cdot \log \left(\mathrm{U}_{\mathrm{it}}^{\mathrm{P}} \mathrm{J}_{\mathrm{it}}\right)+\eta \cdot \log \left(\mathrm{U}_{\mathrm{it}}^{\mathrm{S}} \mathrm{S}_{\mathrm{it}}\right)+\zeta_{\mathrm{it}}
$$

where $\mathrm{y}$ is gross output, $\mathrm{l}$ is labor hours, $\mathrm{S}$ is the structures capital stock, $\mathrm{m}$ is materials (including energy expenditures), $\mathrm{J}$ is the equipment capital stock, $\mathrm{i}$ indexes plants, and $\mathrm{t}$ indexes year $^{17}$. Lowercase letters denote natural logs. The disturbance term, $\zeta_{\mathrm{it}}$, captures stochastic shocks to disembodied technology. It may contain both an aggregate and an idiosyncratic component. Equation (5) is the plant-level analogue of aggregate production function (3).

The variables $\mathrm{U}^{\mathrm{J}}$ and $\mathrm{U}^{\mathrm{S}}$ in equation (5) denote that the utilization rates of equipment and structures capital, respectively. To measure utilization, we follow Petropoulos (1999) who shows that under certain reasonable conditions, the intensity of a plant's energy usage can be used as a proxy for capital utilization. Specifically (suppressing year and plant subscripts), we

\footnotetext{
${ }^{17}$ All variables are in constant dollars unless stated otherwise.
} 
assume:

$$
\mathrm{U}^{\mathrm{J}}=(\mathrm{E} / \mathrm{J})^{\frac{1}{\tau_{\mathrm{J}}}} \text { and } \quad \mathrm{U}^{\mathrm{S}}=(\mathrm{E} / \mathrm{S})^{\frac{1}{\tau_{\mathrm{s}}}}
$$

where E denotes energy expenditures (fuel plus electricity). For purposes of identification, we assume that $\tau_{J}=\tau_{S}=\tau$. Substituting these expressions into the production function (5) and rearranging, we obtain

$$
\begin{aligned}
y_{i t} & =\beta \cdot 1_{i t}+\theta \cdot m_{i t}+[\alpha(\tau-1) / \tau] \cdot \log \left(J_{i t}\right) \\
& +[\eta(\tau-1) / \tau] \cdot \log \left(S_{i t}\right)+[(\alpha+\eta) / \tau] \cdot e_{i t}+\zeta_{i t}
\end{aligned}
$$

where e denotes $\ln (\mathrm{E})$. Observable measures of $\mathrm{q}, 1, \mathrm{~m}$, and e can be readily constructed using variables in the LRD and price deflators from the NBER-CES Productivity Database (hereafter, NBER-CES). ${ }^{18}$

In this paper, we focus on the estimation of the rate of embodied technological change in equipment capital. Therefore, plants' structures capital stock is calculated according to the traditional perpetual inventory definition using historical structures investment from the LRD, price deflators from NBER-CES, and physical decay data from the FRB. Equipment capital, on the other hand, is a parameterized stream of past real equipment investment (net of physical decay):

${ }^{18} \mathrm{~A}$ data appendix describing the construction of each of the variables and containing a description of the properties of our samples can be provided by the authors upon request. 


$$
\mathrm{J}_{\mathrm{t}}=\sum_{\mathrm{s}=1}^{\mathrm{T}} \mathrm{I}_{\mathrm{t}-\mathrm{s}} \mathrm{D}_{\mathrm{t}, \mathrm{t}-\mathrm{s}} \phi_{\mathrm{t}-\mathrm{s}}
$$

where $T$ is the age of the plant, $I_{t-s}$ is real equipment investment of vintage t-s capital goods, $D_{t, t-s}$ is the fraction of one dollar's worth of vintage t-s investment that is still used in production in year $\mathrm{t}$, and $\phi_{t-s}$ is the level of embodied technology in equipment capital of vintage $\mathrm{t}$-s relative to some numeraire year's technology ${ }^{19}{ }^{20}$. This equation is analogous to equation (4) in the 2-sector model. Equation (8) incorporates a one-year time-to-build assumption; that is, new investment is not put into operation until the following year. It takes time to build because of actual assembly requirements or because time is needed to train workers on how to use the new equipment ${ }^{21}$.

Substituting equation (8) into (7) yields the estimating model. Given the large number of parameters and the non-linearity of the model, we found that obtaining estimates (precise or otherwise) of $\phi_{t-s}$ was not possible in all but the most parsimonious of specifications. Thus, for the regressions reported in this paper, we simplify by assuming a constant geometric rate of embodied technological change. This changes the specification of $\mathrm{J}$ to:

${ }^{19}$ In terms of the two-sector model we described earlier, $\phi_{t}$ is the ratio of $q_{t}$ to $q_{0}$ where 0 refers to the numeraire year.

${ }^{20} \mathrm{We}$ assume that investment in vintage t-s capital goods is synonymous with new investment in year t-s. This is incorrect to the extent that there is investment in used capital of earlier vintages. Unfortunately, data on the vintage of a plant's used investment is not available in the LRD. This should have little effect on our results since used investment is typically a negligible part of total investment (new plus used).

${ }^{21}$ We estimated some specifications allowing no time to build but assuming that investment is distributed evenly throughout the year so that, on average, six months' worth of total investment in the newest vintage is used at any one time. The estimates of $\gamma$ are uniformly higher under this specification. 


$$
\mathrm{J}_{\mathrm{t}}=\sum_{\mathrm{s}=1}^{\mathrm{T}} \mathrm{I}_{\mathrm{t}-\mathrm{s}} \mathrm{D}_{\mathrm{t}, \mathrm{t}-\mathrm{s}}(1+\gamma)^{\mathrm{t}-\mathrm{s}-\mathrm{t}_{0}}
$$

where $\gamma$ is the rate of embodied technological change and $t_{0}$ is the numeraire year in which the level of embodied technology is normalized to 1 . We choose 1996, the last year of our data, as the numeraire year. ${ }^{22}$

\section{Discussion of variable capital utilization}

Unmeasured variation in the intensity with which plants utilize capital may lead to biases in production function estimation. We avoid this pitfall by proxying for capital utilization with energy use ${ }^{23}$. The parameter $\tau$ in the assumed functional form (6) is the elasticity of the rate of energy use with respect to capital utilization. It allows for energy use being proportional to capital services (UJ or US, as in Burnside, Eichenbaum, and Rebelo, 1995) when $\tau=1$. For values of $\tau>1$ the marginal cost of capital services increases faster with utilization than with capital stock and at the extreme $(\tau=\infty)$ there is no variation in utilization as it is too expensive.

${ }^{22}$ Equations (8) and (9) provide a way of aggregating vintages that embody different technology levels. Fisher (1965) shows that a necessary and sufficient condition for the existence of a capital aggregate are that the marginal rate of substitution between any pair of inputs within the aggregate be independent of the inputs outside the aggregate. Under constant returns to scale, as Solow (1960) showed, this condition requires that 1) production with each vintage be additively separable, 2) total factor productivity be the same across all vintage production functions at a given year, and 3) investment in a "better" vintage of equipment is equivalent to a larger amount" of investment measured in constant quality.

${ }^{23}$ This approach was suggested by Jorgenson and Griliches (1967) and followed by Burnside et al. (1995) for industry-level estimation and Petropoulos (1999) for plant-level estimation, among others. See Fernald and Basu (1999) for pitfalls arising from unmeasured factor utilization. 
Similarly, when $\tau<1$ the marginal cost of capital services increases slower with utilization than with capital stock and at the extreme $(\tau=0)$ any variation in utilization is achieved by an infinitesimal variation in energy use. ${ }^{24}$

\section{Discussion of physical depreciation assumptions}

Our estimates of the rate of growth of embodied technological change rely importantly on accurate measures of physical depreciation. This is the part of economic depreciation that is due to wear and tear resulting from using the asset in production. We do not use the exponential depreciation rates produced by BEA, which are largely based on the estimates of Hulten and Wykoff (1981), as these reflect both physical deterioration and obsolescence. Instead, we employ the methodology used by BLS and FRB in constructing capital stocks adjusted for the effects of physical depreciation (see Mohr and Gilbert, 1996).

There are two important differences. First, the FRB-BLS methodology results in an ageefficiency schedule that is substantially different from geometric, especially in the early part of an asset's life. Second, the implied rate of depreciation is lower than that for BEA. These features can be seen in Figure 2 which graphs the average depreciation schedule by age in our primary sample for each source of depreciation data. Specifically, for the FRB-BLS depreciation data, this is the average by age (s) over all years ( $t$ ) and plants (i), of the $\mathrm{D}_{\mathrm{i}, \mathrm{t}, \mathrm{t}-\mathrm{s}}$ introduced in equation $(8)^{25}$. The same is done for the $\mathrm{D}_{\mathrm{i}, \mathrm{t}, \mathrm{t}-\mathrm{s}}$ data that is implied by the BEA

${ }^{24}$ Petropoulos (1999) argues that often plants increase capital utilization by "dusting off" older, less efficient machines. Then, increases in utilization would require increasing rates of energy use per unit of capital utilized $(\tau>1)$.

${ }^{25}$ Though $\mathrm{D}_{\mathrm{i}, \mathrm{t}, \mathrm{t}-\mathrm{s}}$ has a plant subscript, empirically this variable is the same for all plants within a 3-digit industry. 
depreciation rates according to the identity $D_{i, t, t-s}=\left(1-\delta_{s}^{\mathrm{BEA}}\right)^{\mathrm{t}-\mathrm{s}}$. Lastly, the depreciation

schedule implied by a $12 \%$ geometric rate is provided as a frame of reference. In the empirical section, we explore the robustness of our estimates of $\gamma$ to different assumptions about physical depreciation.

\section{Data}

The plant-level data we use come from the Longitudinal Research Database (LRD), which is housed at the U.S. Census Bureau's Center for Economic Studies. The LRD consists of annual data on U.S. manufacturing establishments collected in the quinqennial Census of Manufactures (CM) and the Annual Survey of Manufacturing (ASM). At the time of this writing it covers 1963, 1967, and 1972-96.

We construct several data samples with which to estimate equation (3). ${ }^{26}$ Our primary sample is an unbalanced panel consisting of all plant-year observations from plants born in or after 1972 that survived for at least four consecutive years (including the birth year), with the last possible observation year being 1996. Thus, a single plant may have multiple observations in our sample, provided that we continuously observe the plant's equipment investment for every year from birth until the current observation year. Observations from plants born prior to 1972 are excluded as we cannot observe their entire investment history. These missing investment variables would likely have caused substantial biases in estimating the relative efficiency of

${ }^{26}$ We will report results for our primary sample only. Results using other samples are available from the authors upon request. 
different vintages of investment. An alternative sample was contructed in order to test the robustness of our results to the possiblity of sample selection bias introduced by the exclusion of plants born prior to 1972 . The results are robust to this change of sample (results from alternative samples are available from authors upon request).

We keep only observations from plants that have survived at least four consecutive years in an effort to avoid two possible problems. First, the factor elasticities, particularly for capital, in the first three years of a plant's operations have been shown to be significantly different than those in later years (see Bahk and Gort (1993)). In fact, the elasticity of output with respect to capital is often found to be statistically insignificant in the first few years. Bahk and Gort attribute this phenomenon to learning by doing. Second, data in the LRD is imputed for a substantial portion of any given year's newly-born plants (with the exception of data on industry, employment, and payroll). Thus, data from the first year of plants is fraught with measurement error. Since we utilize the entire investment history of a plant, we are not immune to the measurement error introduced by imputation of the first year's equipment investment. However, the share of investment that is imputed becomes smaller and smaller as the plant ages and thus, it is hoped, its impact should be minimal by the fourth year. Using an alternative sample that retained observations of two- and three-year old plants, we found that our results do not appear to be biased by their exclusion (alternative sample results available from authors upon request).

\section{Is our Sample Representative of Manufacturing?}

Our primary sample consists of a total of 96,846 plant-year observations covering 24,404 plants. We performed a detailed comparison of this sample to the other samples we use and to the aggregate manufacturing sector (the results of which can be provided by the authors upon 
request). In terms of the dynamic behavior of its plants, this sample is quite representative of the manufacturing sector as a whole. The average growth rates of investment and employment are quite similar over the 1975-96 period. This is true even though the sample, due to the nature of the LRD, consists of plants that are larger, on average, than the typical manufacturing plant (in terms of gross shipments, employment, or investment) as aggregate activity is primarily shaped by large plants. The sample distribution of shipments across 2-digit SIC industries is also quite representative of manufacturing though there is a tendency to under-represent mature-plant industries such as Petroleum and over-represent young-plant industries such as Communications.

\section{Results}

In this section we present the results of our estimation. We employ non-linear least squares (NLLS) with a heteroskedasticity- and autocorrelation-consistent (HAC) variancecovariance matrix. The HAC VC matrix is necessary because autocorrelation of the errors is likely due to the fact that the same plant can have multiple observations in our sample. All regressions include year and industry dummies as well as industry-specific time trends. In addition, we include a dummy variable, which we call Multi, indicating whether the plant is part of a firm that operates multiple plants. Table 1 contains our main results.

Initially, we do not allow for variable capital utilization by setting $\tau=\infty$. As may be seen in column (A), the rate of growth of embodied technological change, $\gamma$, is estimated to be a little under 8 percent. This is higher than the rate calculated in the price-based approaches using Gordon's (1990) data. The coefficient on Multi indicates that plants in a multi-establishment 
firm have on average 8.7 percent higher TFP than single-establishment firms, other things equal. This is consistent with past results in the plant-level literature (see, e.g., Baily, Hulten, and Campbell (1992)). The estimated factor elasticities are quite close to observed factor shares with the exception of the capital coefficients, which are a bit lower. ${ }^{27}$

The data seem to support allowing for variable capital utilization, at least as proxied by energy use. As may be seen in Column (B), the estimate of $\tau$ is 2.08 (with a standard error of 0.09). This value implies that the marginal cost of capital services (UJ or $U S$ ) increases faster with utilization than with capital stock. In particular, the Leontief assumption employed by Jorgenson and Griliches (1967) and Burnside et al. (1995), $\tau=1$, is rejected by our data. The estimated elasticities of capital and labor change in the direction one would expect if plants vary their capital utilization significantly in response to shocks. Not taking such variation into account creates an omitted variable likely to be positively correlated with employment (biasing its coefficient upward) and negatively correlated with the stock of capital (biasing its coefficient downward $)^{28}$.

As may be seen in (B) controlling for variation in utilization reduces the coefficient of labor by 2 percent while it increases the sum of the coefficients of capital by more than a third bringing the ratio of the elasticities of labor and capital to about 2 to 1 , as expected. Returns to scale are estimated to be 0.98 which is not statistically significantly different from one. The

\footnotetext{
${ }^{27}$ Allowing factor elasticities to vary by industry yields a slightly lower estimate of $\gamma$ of 0.055 (0.028). However, many of the estimated elasticities are nonsensical, particularly those for structures. It appears allowing industry-varying elasticities may be asking too much from the data and therefore we maintain the assumption of common elasticities for the regressions to follow.
}

${ }^{28}$ For plant-level evidence on these patterns of correlation see Sakellaris (2000). 
estimate of $\gamma$ is much higher now at 17 percent. This implies a vastly higher rate of embodied technological change than is usually considered.

\section{Learning Effects}

Several papers since Arrow (1962) have suggested that the installation of new equipment embodying improved technology may involve significant subsequent investments in training workers as well as experimentation in the organization of production. These would tend to reduce productivity initially while raising it eventually and Arrow (1962) termed this process "learning by doing." 29 Ignoring such learning effects might bias our estimate of $\gamma$, though the direction of the bias is not clear. To explore the extent of such problems we repeat our estimation including an indicator of whether the plant undertook an equipment-investment spike together with seven lags of it. ${ }^{30}$ Our idea is that spikes are associated with most instances of an introduction of a new and "better" vintage of technology and the inclusion of the spike indicators should control for learning effects on productivity. As may be seen in column $\mathrm{C}$ of Table 1 , the estimate of $\gamma$ is about 12 percent and the rest of the coefficients do not change much. ${ }^{31}$

\section{Average Vintage Effect}

\footnotetext{
${ }^{29}$ See Greenwood and Jovanovic (1998) for an extensive analysis of the macroeconomic implications of learning-by-doing as well as references to some recent work.

${ }^{30}$ We identify a spike with observations of equipment investment to capital ratios greater than 0.20. See Power (1998), Doms and Dunne (1998), Cooper et al. (1999) and Sakellaris (2000) for justification of using this definition at the plant level.

${ }^{31}$ The coefficients on the spike indicators show an approximately $6 \%$ drop in productivity in the first year after a spike with slow recovery thereafter.
} 
In Section 3 we mentioned that an alternative production-based approach which obtains $\gamma$ via the estimated coefficient on average age or vintage is due to Nelson (1964). In the most parsimonious case where one does not allow for unobserved utilization or learning effects, this approach leads to the following specification (ignoring the constant, the error term, and time and industry dummies):

$$
y_{i t}=\rho \cdot t+\beta \cdot 1_{i t}+\theta \cdot m_{i t}+\eta \cdot s_{i t}+\alpha \cdot j_{i t}^{\prime}+\alpha \cdot \log \left(1+\gamma \bar{V}_{i t}\right)
$$

where $\mathrm{j}^{\prime}$ is log equipment capital unadjusted for embodied technological change (i.e. $\mathrm{j}^{\prime}$ is just $\mathrm{j}$

from equation 14 with $\gamma$ set equal to zero) and $\bar{V}$ is the average vintage of equipment for plant I

in year t. Generally, $\gamma \overline{\mathrm{V}}$ is assumed to be close to zero allowing the last term in (10) to be

approximated by $\alpha \gamma \overline{\mathrm{V}}_{\mathrm{it}}$. In our sample, however, the mean (over all plant-year observations)

average vintage is approximately 12 (corresponding to 1984). The product of 12 and even a very small $\gamma$, say 0.01 , will still be far from zero suggesting that serious specification errors are likely when we estimate (10).

In fact, as shown in column (D) of Table 1, the Nelson method yields the rather implausible estimate of 27 percent for $\gamma$ which is significantly different from the 12 percent found using our method.

\section{Industry heterogeneity}

One concern we have is that the dynamic behavior of output, inputs, and disembodied technological change may differ substantially across industries. A prominent example is the 
computer sector which has enjoyed rapid growth in its productivity relative to other manufacturing industries and a correspondingly rapid relative decline in its price index. In order to control for this we included a set of industry-specific time trends in each of our regressions. All industry trends were estimated between \pm 1 percent with the important exceptions of computers $(8.3 \%)$ and communication equipment $(3.3 \%) .{ }^{32}$ Given that the computer industry has such a high rate of disembodied technological change, it is natural to wonder whether the computer industry is the primary driver of our high estimates of $\gamma$. Omitting the computer industry decreases our estimate from 0.116 to 0.070 (with a std. error of 0.053 ). Thus, it appears the computer industry is $a$ but probably not the primary driver of economy-wide embodied technology.

\section{Time variation in the parameters}

One may also be concerned with whether $\gamma$ has varied greatly over time. To test this, we estimate our full specification allowing $\gamma$ to vary by year and test the hypothesis that $\gamma$ is constant. The F-statistic for this test is 0.17 compared to a $95 \%$ critical value of 1.00 . Thus, one cannot reject the hypothesis of a constant $\gamma$ over cross-sectional years.

Another concern is whether our pooled estimate of $\gamma$ is affected by the assumption that the elasticity of energy usage with respect to capital utilization, $\tau$, is constant. It is possible that $\tau$ was higher in the 1970's when energy costs were high than it was in the 1980's and 1990's. It can easily be shown that the contribution of equipment capital to output, $\alpha(\tau-1) / \tau$, is increasing

\footnotetext{
${ }^{32}$ These estimates refer to the regression in Column $\mathrm{C}$ though the corresponding estimates from the other regressions are quite similar. We were able to reject the hypothesis that industries do have a common time trend via a Wald test at a $99 \%$ level of confidence. The F-statistic is 84.5 , far greater than the $99 \%$ critical value of 1.8 .
} 
in $\tau$. If estimated $\tau$ is constrained to be constant whereas, in reality, it was higher early on then the contribution of early vintage equipment to output would be understated. To compensate, OLS will tend to overweight early vintage investment relative to later investment in order to minimize SSE. This implies an downward bias in $\hat{\gamma}$ when constraining $\tau$ to be constant. However, allowing $\tau$ to vary by year and estimating our full specification over the pooled sample yields a gamma of 0.127 (0.054) compared to the $0.116(0.060)$ in Table 1 , Column C. Furthermore, $\tau_{t}$ does exhibit a slightly rising trend over time, which is statistically significant according to a Wald test. ${ }^{33}$

\section{Alternative Depreciation Assumptions}

The estimate of $\gamma$ depends on the assumption for physical depreciation. We now entertain the possibility that physical depreciation rates are near-geometric and amount to various fractions of the BEA rates. We construct the parameterized capital stock assuming that physical depreciation is a constant fraction of the BEA-provided rate for each observation's industry and year. We then estimate how $\gamma$ varies.

Table 3 and Figure 3 contain the results. As expected, the lower is the assumed depreciation rate the higher is the estimate of $\gamma$, which ranges from 0 to 25 percent (with standard errors ranging from 4 to 6 percent). Clearly as we allow less of the decrease in productivity of early vintages of investment over time to be explained by physical decay, $\gamma$ is left to explain more of this decrease. Total economic depreciation, the sum of physical decay and obsolescence, ranges from 13 to 25 percent. Also shown in Figure 3 is the average BEA

\footnotetext{
${ }^{33}$ The F-statistic for the test of the null hypothesis that $\tau$ is constant for all years is $8.48>\mathrm{F}_{\mathrm{J}, \mathrm{T}-\mathrm{K}}(.95)=1.00$.
} 
economic depreciation rate of $12 \%$ and the implied rates of obsolescence as the physical depreciation rate is increased.

To conclude, even with geometric physical depreciation the estimated rate of embodied technological change is high except in the case where the BEA rates are assumed to reflect physical depreciation and no obsolescence. It is straightforward to show theoretically that in the latter case one excludes the possibility of embodied technological change by assumption. ${ }^{34}$

\section{Simultaneity Bias}

It is well known that OLS estimation of production function relationships is subject to potential simultaneity biases ${ }^{35}$. Since the "independent" variables are production inputs that are chosen optimally by the producers, the usual exogeneity assumptions that are required for the consistency of OLS may fail. A plant manager's input choices are determined by plant quality (or, equivalently, managerial efficiency, or disembodied technology) along with factor prices and product demand. Since part of this quality is unobserved by the econometrician, it is subsumed into the disturbance term of the production function. The result is that variable inputs may be correlated with the disturbance term.

To address the possibility of simultaneity bias, we attempted a non-linear instrumental variables (NLIV) estimation. An appropriate set of instrumental variables should include all exogenous variables in the model together with other exogenous and relevant (i.e. correlated

${ }^{34}$ Deflating by the equipment-investment deflator instead of the PCE deflator and repeating the estimation does not change our conclusions.

${ }^{35}$ Marschak and Andrews (1944) were the first to recognize this problem. Griliches and Mairesse (1995) provide a thorough discussion of the issue together with attempts to ameliorate the problem using plant-level data. 
with the Jacobian vector of first derivatives of the model with respect to the parameter vector) instruments. For identification it is necessary to have at least one instrument per parameter to be estimated. Unfortunately, it is very difficult to find good instruments (exogenous and relevant) at the plant level for our purposes. This limits severely the success of our NLIV estimations as we will see below. In order to address these problems partially, we try to minimize the number of parameters to be estimated by following a suggestion of Griliches and Ringstad (1971). We replace factor elasticities of some or all of the inputs (e.g. of materials and labor) with measures of their share in cost (using 4-digit industry-level data from the NBER-CES Productivity Database and 2-digit equipment and structures rental rates from the BLS). This leaves in some cases $\gamma$, and $\tau$ as the only parameters to be estimated.

For instruments, we use the set of 4-digit industry-level downstream demand indicators originally constructed by Bartelsman, Caballero, and Lyons (1994) and modified by Baily, Bartelsman, and Haltiwanger (2001). An industry's demand indicator is a weighted average of the economic activity of manufacturing and service industries (downstream industries) that purchase the industry's output. The weights are the share of each downstream industry's purchases in the upstream industry's total output and the measure of economic activity is the sum of the cost-share weighted growth rates of each factor input (capital, labor, and materials). In order to filter out any endogenous effect that an upstream industry's productivity may have, through its output price, on downstream industries' activity, the indicator excludes the activity of downstream industries whose purchases from the upstream industry are greater than $5 \%$ of their total intermediate input purchases. The instrument set also includes the second through fourth powers of this downstream demand indicator, and investment lagged 3 through 24 years (24 is 
oldest possible non-zero lagged investment that a plant in our sample can possibly have). ${ }^{36}$

The results of these regressions are shown in Table 4. Column A shows the regression results from our preferred specification where labor's and material's elasticities are not estimated but rather are measured by their industry cost shares. Column B shows the results from the same regression except that all factor elasticities are measured by their industry cost shares and no utilization adjustment is made. ${ }^{37}$ Column $\mathrm{C}$ contains results from an average vintage specification also without a utilization adjustment and with all factor elasticities measured by cost shares.

The results of our IV estimations are inconclusive. Largely due to the inclusion of lagged investment in our instrument set, our first-stage $\mathrm{R}^{2}$ 's (not shown) are fairly high, particularly for the first derivative of $\gamma$. Yet, despite this apparent relevance, we are not able to estimate $\gamma$ with any reasonable degree of precision. Of the three regressions shown, only the estimate of $\gamma$ in column B is significant. Based on unreported OLS results we conclude that the negativity of $\hat{\gamma}$ is most likely due to the imposition of the industry cost-shares rather than to the use of IV. In summary, despite our efforts to instrument for endogeneity, we are not able to rule out the possibility of simultaneity bias in our estimate of $\gamma$.

Why do we not use the Olley and Pakes (1996) method?

\footnotetext{
${ }^{36}$ It may be argued that past investment, even lagged more than three years, is endogenous. Unfortunately, when we omit lagged investment from our set of instruments, our first-stage $\mathrm{R}^{2}$ drops substantially and the standard errors rise making the estimates essentially meaningless. regression.

${ }^{37}$ The iterative estimation procedure was not able to converge when $\tau$ was included in the
} 
Olley and Pakes (1996) present a model of plant behavior that motivates a three-stage algorithm for estimating a production function while controlling for factor endogeneity and selection bias due to endogenous exit. The model relies crucially on an "invertibility condition." This amounts to investment being a monotonic function of unobserved productivity, and observed capital stock. This allows productivity to be expressed as an inverse function of investment and capital stock.

Unfortunately, this approach is not appropriate for our model, which allows for embodied technological change. The problem is that capital stock is not an observed plant state variable in our approach. We use a parameterized stream of current and past investment rather than a capital stock construct. This renders unidentifiable the separate effects of embodied technology in current investment and the productivity signal of current investment.

\section{Productivity growth decomposition}

Our findings have the important implication that the equipment capital stock is mismeasured considerably in studies of productivity growth or production function estimation. In particular, we estimate that the stock of equipment grows at much faster rates than is reflected in conventional methods. As may be seen in Table 5, the growth rate of equipment capital stocks depends crucially on the assumptions made on physical depreciation, the investment-price deflator, and the rate of growth of embodied technological change. ${ }^{38}$ For both our primary plant-

\footnotetext{
${ }^{38}$ For the construction of these capital stocks, a numeraire year $\left(\mathrm{t}_{0}\right)$ of 1972 was used. The choice of numeraire year can affect whether the growth rate of capital is monotonically increasing or monotonically decreasing in $\gamma$. This can be seen easily by taking the derivative of $\left(\mathrm{J}_{\mathrm{t}} / \mathrm{J}_{\mathrm{t}-1}\right)$ with respect to gamma where $\mathrm{J}_{\mathrm{t}}$ is defined according to equation (14). Choosing a numeraire year at the beginning of our sample ensures that the growth rate will increase with $\gamma$.
} 
level sample and for the aggregate manufacturing data (from BEA), we calculate the annual growth rate of equipment capital stock under six different sets of assumptions. ${ }^{39}$ The growth rate of the stock implied by the results from our main regression (Column $\mathrm{C}$ of Table 1), with $\gamma=0.116$, is 14.7 percent in our sample and 14.0 percent in the aggregate data. This is substantially higher than the growth rate of the conventional capital stock $(\gamma=0$, investment deflated by the FRB/PPI investment deflators and adjusted for depreciation using the BEA/Hulten-Wykoff rates), which is 4.2 percent in our sample and 3.0 in the aggregate. It is also far above the growth rates of the capital stocks endorsed by either Hulten (1992) or Greenwood, et al. (1997). The key element that generates the higher growth rate in our capital stock construct is the value of $\gamma$. When we set $\gamma$ to zero but use the FRB/BLS depreciation data and the PCE deflator to construct the capital stock its growth rate is only 4.4 percent in our sample and 2.1 in the aggregate.

What is the relative importance of embodied and disembodied technological change for productivity growth in our sample of U.S. manufacturing plants? According to equation (3), the residual growth rate in output, after accounting for quality-adjusted input growth, is due to technological change that is not embodied in equipment investment. That growth rate in our sample is 0.57 percent annually. ${ }^{40}$ Correspondingly, the rate of output growth that is due to embodied technological change is equal to the equipment elasticity times the differential growth

What is important for comparing capital stock growth rates using different $\gamma$ 's is not necessarily the sign of this derivative, but just that the derivative is monotonic in $\gamma$.

${ }^{39}$ Specifically, we regress the log of equipment capital stock on $t$ and an intercept. The coefficient on year gives the average annual growth rate.

${ }^{40}$ This number is the coefficient on time in a regression of the log of TFP, constructed using the equipment capital stock with a $\gamma=.116$, on time and an intercept. 
rate of quality-adjusted and non-quality adjusted equipment capital stocks. This measure averages 1.17 percent annually in our sample. ${ }^{41}$ The implication is that equipment-embodied technological change accounted for about two-thirds of total technological change between 1972 and 1996 in our sample of U.S. manufacturing plants.

\section{Conclusion}

Assessing the rate of embodied technological change is of high importance. It is a necessary ingredient for productivity analysis and for constructing accurate measures of capital accumulation. Furthermore, it tells us how much of the decline in an asset's value as it ages can be attributed to obsolescence.

In this paper, we develop a production-side approach that provides alternative estimates of embodied technological change without relying on accurate measurement of price indices for producer durable equipment. We find that the rate of embodied technological change is between 8 and 17 percent with our preferred estimate being 12 percent. These rates are much higher than that captured by the relative rate of decline of Gordon's (1990) equipment price deflators which puts it no higher than $4 \%$. Our results are consistent with arguments made by Hornstein and Krusell (1996), Gort and Wall (1998), and others who argue that these price-based estimates are likely to understate true embodied technological change.

If our estimates are accurate, embodied technological change may account for as much as

41 The equipment elasticity is 0.114 from Column $\mathrm{C}$ of Table 1 . The approximate annual growth rate in the equipment capital stock due to embodied technological change is 10.3 percent. This number comes from subtracting the 14.7 percent estimate in Row A of Table 6 from the 4.4 percent estimate in Row C. 
two-thirds of the total growth in TFP of manufacturing plants between 1972 and 1996, suggesting an important role for investment in spurring productivity growth above and beyond its traditional role of capital deepening. 


\section{REFERENCES}

Arrow, Kenneth. "The Economic Implications of Learning by Doing." Review of Economic Studies, 29(3), June 1962, pp. 155-173.

Bahk, Byong-Hyong, and Gort, Michael. "Decomposing Learning by Doing in New Plants." Journal of Political Economy, 101(4), August 1993, pp. 561-583.

Baily, Martin; Bartelsman, Eric; and Haltiwanger, John. "Labor Productivity: Structural Change and Cyclical Dynamics." Review of Economics and Statistics, August 2001, 83(3): 420-33.

Bartelsman, Eric, Caballero, Ricardo, and Lyons, Richard. "Customer- and Supplier-Driven Externalities." American Economic Review, September 1994, 84(4), pp. 1075-84.

Bartelsman, Eric J., and Gray, Wayne. "The NBER Manufacturing Productivity Database." NBER Technical Working Paper 205, October 1996.

Basu, Susanto and Fernald, John. "Why is Productivity Procyclical? Why Do We Care?" Board of Governors of the Federal Reserve System, IFDP no. 638, June 1999.

Burnside, Craig; Eichenbaum, Martin; and Rebelo, Sergio. "Capital Utilization and Returns to Scale.” In NBER Macroeconomics Annual 1995. Editors Julio J. Rotemberg and Ben S. Bernanke. Cambridge, MA: MIT Press, 1995.

Cooper, Russell; Haltiwanger, John; and Power, Laura. "Machine Replacement and the Business Cycle: Lumps and Bumps." American Economic Review, December 1999, 89(4), pp. 921-46.

Davis, Steven; Haltiwanger, John; and Schuh, Scott. Job Creation and Destruction. Cambridge, MA: MIT Press, 1996.

Doms, Mark, and Timothy Dunne. "Capital Adjustment Patterns in Manufacturing Plants." Center for Economic Studies Discussion Paper 94-11, August 1994.

Eaton, Jonathan and Samuel Kortum. "Trade in Capital Goods," NBER working paper \# 8070, January 2001.

Fisher, Franklin M. "Embodied Technical Change and the Existence of an Aggregate Capital Stock." Review of Economic Studies, 32, October 1965, pp. 263-88.

Gordon, Robert J. The Measurement of Durable Goods Prices. Chicago: University of Chicago Press, 1990.

Gordon, Robert J. "Can Technology Improvements Cause Productivity Slowdowns? Comment." In NBER Macroeconomics Annual 1996. Editors Julio J. Rotemberg and Ben S. Bernanke. Cambridge, MA: MIT Press, 1996.

Gort, Michael, and Richard Wall. "Obsolescence, Input Augmentation, and Growth Accounting." European Economic Review, 42, 1998, pp. 1653-65.

Greenwood, Jeremy; Hercowitz, Zvi; and Krusell, Per. "Long-Run Implications of Investment-Specific Technological Change." American Economic Review, June 1997, 87(3), pp. 342-362.

Greenwood, Jeremy; Hercowitz, Zvi; and Krusell, Per. "The Role of Investment-specific Technological Change in the Business Cycle." European Economic Review, 44(2), April 2000, pp. 91-115.

Greenwood, Jeremy, and Jovanovic, Boyan. "Accounting for Growth.” Mimeo, June 1998.

Greenwood, Jeremy, and Mehmet Yorukoglu. "1974." Carnegie-Rochester Conference Series on 
Public Policy, 46(0), 1997, pp. 49-95.

Griliches, Zvi, and Mairesse, Jacques. "Production Functions: The Search for Identification." NBER Working Paper No. 5067, March 1995.

Griliches, Zvi, and Ringstad, V. Economies of Scale and the Form of the Production Function. Amsterdam: North-Holland, 1971.

Hercowitz, Zvi. “The 'embodiment' hypothesis.” Journal of Monetary Economics, 41(1), February 1998, pp. 217-24.

Hobijn, Bart. "Embodiment in U.S. Manufacturing," mimeo, Federal Reserve Bank of New York, March 2001.

Hornstein, Andreas, and Krusell, Per. "Can technology improvements cause productivity slowdowns?" In NBER Macroeconomics Annual 1996. Editors Julio J. Rotemberg and Ben S. Bernanke. Cambridge, MA: MIT Press, 1996.

Hulten, Charles. "Growth Accounting when Technical Change is Embodied in Capital." American Economic Review, September 1992, 82(4), pp. 964-980.

Hulten, Charles and Frank Wykoff. "The Measurement of Economic Depreciation." Depreciation, Inflation, and the Taxation of Income From Capital. Editor Charles Hulten, pp. 81-125. Washington, D.C.: Urban Institute, 1981.

Jorgenson, Dale W., and Griliches, Zvi. "The Explanation of Productivity Change." Review of Economic Studies, 1967, 34, pp. 249-83.

Johansen, Leif. "Substitution versus Fixed Proportion Coefficients in the Theory of Economic Growth," Econometrica, 1944, 12(3/4), pp. 143-205.

Jovanovic, Boyan and Rafael Rob. "Solow vs. Solow," 1999, mimeo, NYU.

Marschak, Jacob, and William Andrews. "Random Simultaneous Equations and the Theory of Production." Econometrica, 1944, 12(3/4), pp. 143-205.

Mohr, Michael, and Gilbert, Charles. "Capital Stock Estimates for Manufacturing Industries: Methods and Data." Board of Governors of the Federal Reserve System, March 1996.

Nelson, Richard. "Aggregate Production Functions and Medium-Range Growth Projections." American Economic Review, September 1964, 54(5), pp. 575-606.

Olley, Steven and Pakes, Ariel. "The Dynamics of Productivity in the Telecommunications Equipment Industry." Econometrica, 55(4), 1996, pp.1263-98.

Petropoulos, Wendy. "Industry Productivity Dynamics and Unmeasured Capacity Utilization." Mimeo, University of Michigan, November 1999.

Power, Laura. "The Missing Link: Technology, Investment, and Productivity." Review of Economics and Statistics, May 1998, 80(2), pp. 300-313.

Sakellaris, Plutarchos. "Patterns of Plant Adjustment," mimeo, University of Maryland, August 2000.

Shea, John. “Do Supply Curves Slope Up?” Quarterly Journal of Economics, 1993, 108(1), pp.1-32.

Solow, Robert. "Investment and Technical Progress." In Kenneth Arrow, Samuel Karlin, and Patrick Suppes, eds., Mathematical Methods in the Social Sciences. Stanford, CA: Stanford University Press, 1960, pp. 89-104. 


\section{Table 1}

\begin{tabular}{|l|l|l|l|l|}
\hline Parameter & \multicolumn{1}{c|}{$\mathrm{A}$} & \multicolumn{1}{c|}{$\mathrm{B}$} & \multicolumn{1}{c|}{$\mathrm{C}$} & \multicolumn{1}{c|}{$\mathrm{D}$} \\
\hline$\gamma$ & $0.077(0.029)$ & $0.169(0.049)$ & $0.116(0.060)$ & $0.271(0.059)$ \\
\hline Intercept & $2.298(0.049)$ & $2.421(0.054)$ & $2.369(0.080)$ & $-1.183(1.077)$ \\
\hline Multi & $0.087(0.008)$ & $0.079(0.008)$ & $0.080(0.008)$ & $0.080(0.005)$ \\
\hline$\beta$ & $0.344(0.005)$ & $0.322(0.005)$ & $0.319(0.005)$ & $0.318(0.002)$ \\
\hline$\Theta$ & $0.545(0.005)$ & $0.531(0.005)$ & $0.529(0.005)$ & $0.529(0.002)$ \\
\hline$\alpha$ & $0.078(0.003)$ & $0.108(0.005)$ & $0.114(0.005)$ & $0.114(0.002)$ \\
\hline$\eta$ & $0.008(0.002)$ & $0.020(0.004)$ & $0.018(0.004)$ & $0.019(0.002)$ \\
\hline$\tau$ & & $2.076(0.091)$ & $2.219(0.105)$ & $2.232(0.050)$ \\
\hline Adjusted $\mathrm{R}^{2}$ & 0.926 & 0.927 & 0.927 & 0.927 \\
\hline
\end{tabular}

A: Base regression (does not allow for capital utilization or learning-by-doing effects).

B: Adjusts for capital utilization using energy expenditures (see equation 11).

C: Full specification (adjusts for capital utilization and includes variables capturing learning-bydoing effects associated with investment spikes).

D: Average vintage regression (see equation 15).

Note: Regressions A-D also included year and industry dummy variables as well as industryspecific time trends. The coefficients on these are not shown in order to conserve space. They can be obtained from the authors upon request. 
Table 2

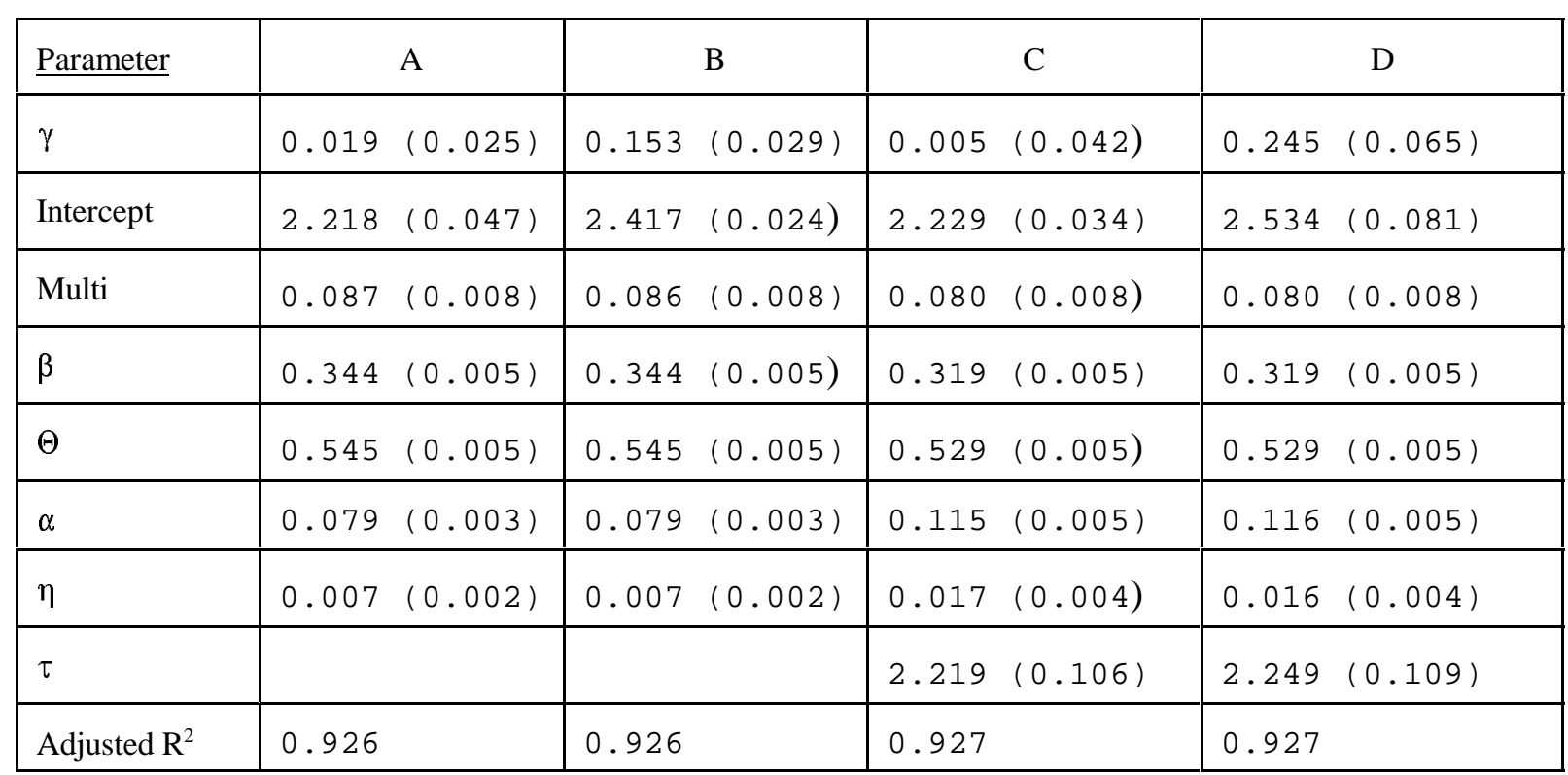

A: Base regression (does not allow for capital utilization or learning-by-doing effects); physical decay measured by BEA economic depreciation rates.

B: Base regression; no physical decay allowed for.

C: Full specification (adjusts for capital utilization and includes variables capturing learning-bydoing effects associated with investment spikes); physical decay measured by BEA economic depreciation rates.

D: Full specification; no physical decay allowed for.

Note: Regressions A-D include year and industry dummy variables which are not shown in order to conserve space. They can be obtained from the authors upon request. 


\section{Table 3}

\begin{tabular}{|c|c|c|}
\hline Fraction of BEA rates & Estimated $\gamma$ & $\begin{array}{c}\text { Implied Economic } \\
\text { Depreciation Rate }^{1}\end{array}$ \\
\hline 0 & $0.245(0.065)$ & 0.245 \\
\hline 0.25 & $0.205(0.064)$ & 0.236 \\
\hline 0.5 & $0.159(0.061)$ & 0.220 \\
\hline 0.75 & $0.087(0.053)$ & 0.178 \\
\hline 1 & $0.005(0.042)$ & 0.126 \\
\hline
\end{tabular}

Note: All of the estimates in column 2 were obtained using the same, preferred specification: adjustment to control for unobserved utilization and spike dummies included to control for learning-by-doing effects (i.e., the same specification as was used in Table 1, Column C).

${ }^{1}($ Column 1$) *($ Average BEA depreciation rate $=0.121)+($ Column 2$)$. 


\section{Table 4}

\begin{tabular}{|c|c|c|c|}
\hline & $\mathrm{A}$ & $\mathrm{B}$ & $\mathrm{C}$ \\
\hline$\gamma$ & $0.332(0.319)$ & $-0.134(0.048)$ & $0.144(0.098)$ \\
\hline Intercept & $-0.030(0.980)$ & $1.519(0.029)$ & $2.494(1.006)$ \\
\hline$\alpha$ & $0.166(0.033)$ & & \\
\hline$\eta$ & $0.112(0.030)$ & & $0.049(0.010)$ \\
\hline Multi & $-0.269(0.047)$ & $0.058(0.011)$ & $0.947(0.006)$ \\
\hline Scale & 1.000 & $0.939(0.007)$ & 1.000 \\
\hline $\begin{array}{c}\text { P-value for Test } \\
\text { of over- } \\
\text { identifying } \\
\text { restrictions }\end{array}$ & 0.905 & 1.000 & 0.906 \\
\hline \begin{tabular}{c} 
Adjusted ${ }^{2}$ \\
\hline
\end{tabular} & & 0.905 & \\
\hline
\end{tabular}

A: Regression with labor and materials elasticities measured by industry cost-shares.

B: Regression with all factor elasticities measured by industry cost-shares.

$\mathrm{C}$ : Average vintage regression with all factor elasticities measured by industry-level cost-shares. Note: Regressions A-C also include year and industry dummy variables. 


\section{Table 5}

Annual Growth Rate from 1972-96

\section{Type of Equipment Capital Stock}

A. This paper -- $\gamma=11.6 \%$

B. This paper -- $\gamma=7.7 \%$

C. This paper $--\gamma=0$

D. Conventional

E. Hulten (1992)

F. Greenwood, et al. (1997)
Our Sample

$14.7 \%$

$11.2 \%$

$4.4 \%$

$4.2 \%$

$7.0 \%$

$7.0 \%$
Aggregate Manufacturing

$14.0 \%$

$10.0 \%$

$2.1 \%$

$3.0 \%$

$6.0 \%$

$5.7 \%$

A -- The equipment capital stock implied by the $\gamma$ found in Table 1, Column C: $\gamma=0.116$ and the FRB physical depreciation schedules and the PCE deflator are used.

B -- $\gamma=0.077$, FRB physical depreciation, and PCE deflator.

$\mathrm{C}--\gamma=0$, FRB physical depreciation, and PCE deflator.

$\mathrm{D}--\gamma=0$, BEA depreciation, and FRB/PPI investment deflators.

$\mathrm{E}--\gamma=0.03$, BEA depreciation, and FRB/PPI investment deflators.

$\mathrm{F}--\gamma=0.03$, BEA depreciation, and deflator for PCE of nondurables and nonhousing services. 


\section{FIGURE 1}

PCE deflator vs. average FRB equipment deflator used in our sample from 1972-96

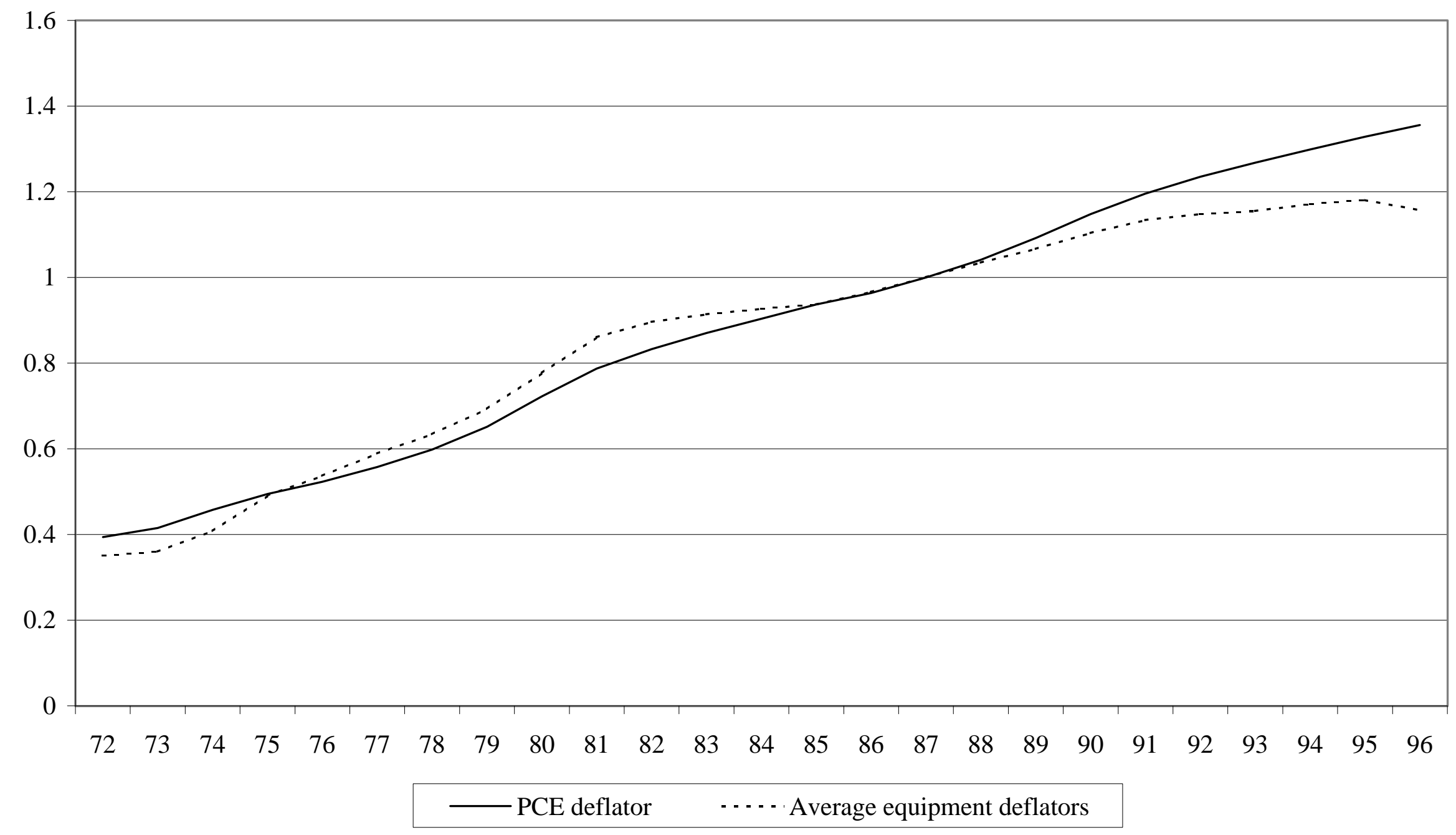


FIGURE 2

\section{Average Depreciation Pattern}

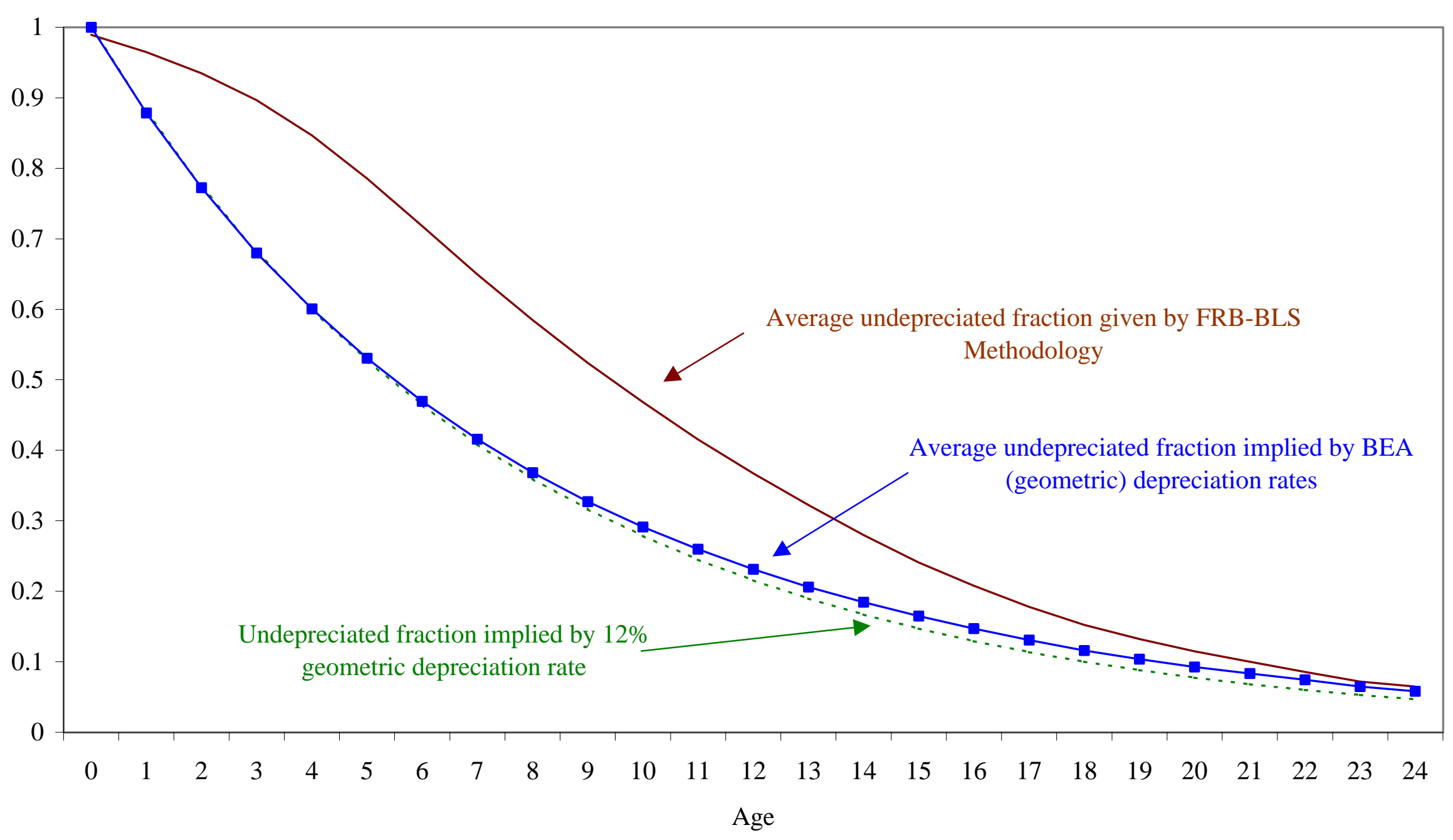




\section{Figure 3}

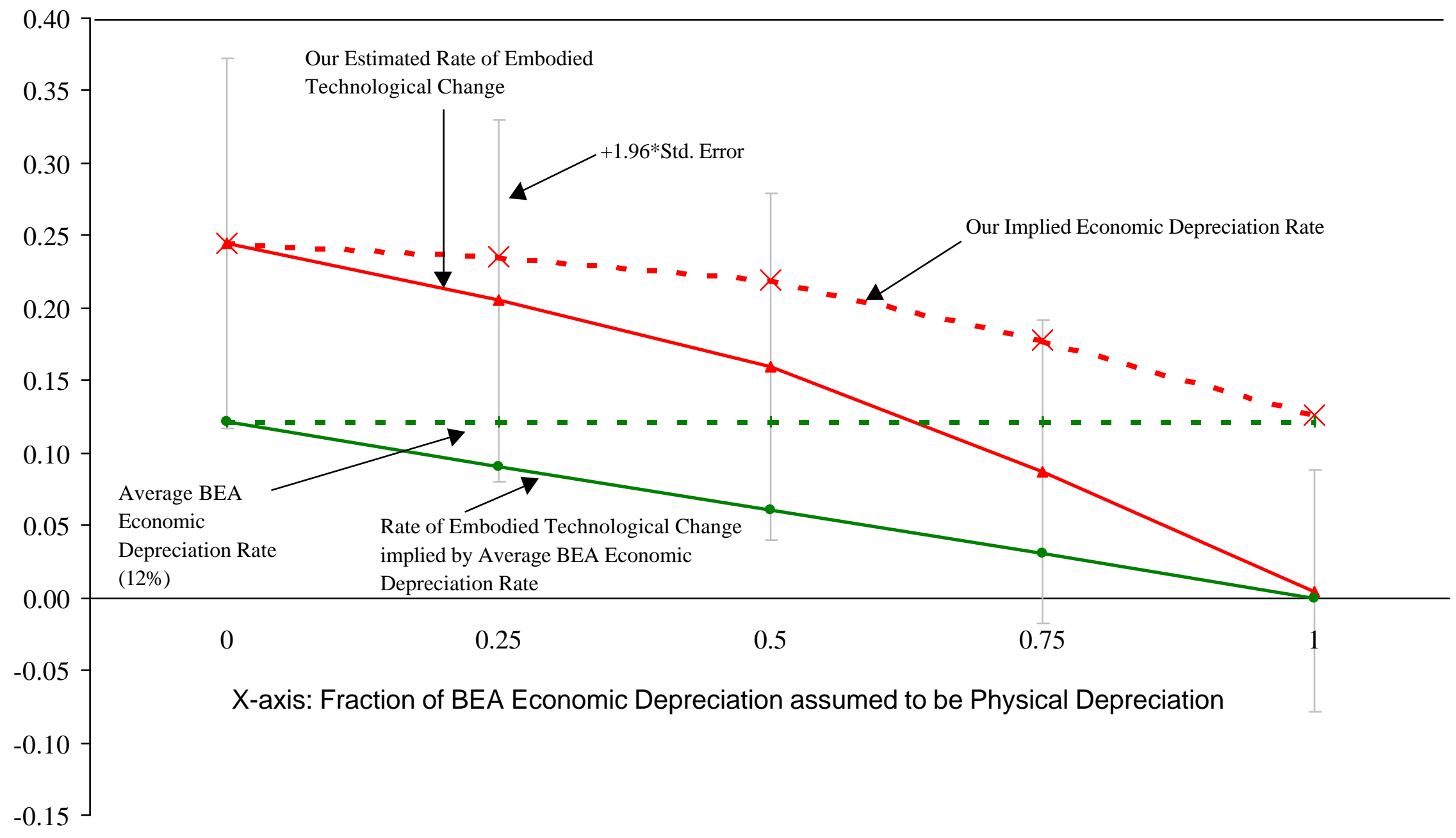

